\title{
Actitudes de madres de familia frente a la sordera de sus hijos: caso en un aula básica para sordos*
}

Volumen $5 \mathrm{~N} .042$ enero - junio de 2017

ISSN: 0122-4328

ISSN-E: 2619-6069

pp. 101-116

\author{
Attitudes of Mothers \\ in the Face of Their \\ Children's Deafness: \\ Case in a Beginner's \\ Class for the Deaf
}

\author{
Atitudes de mães \\ de família frente à \\ surdez de seus filhos: \\ caso em uma sala \\ de aula básica para \\ surdos
}

\section{Luz del Sol Vesga Parra** \\ Julieth Jakelín Trujillo Pinto*** Karen Viviana Agudelo Rico****}

Fecha de recepción: 02-08-2016

Fecha de aprobación: 03-03-2017

\section{PARA CITAR ESTE ARTÍCULO}

Vesga, L. y Trujillo, J. y Agudelo, K. (2017). Actitudes de madres de familia frente a la sordera de sus hijos: caso en un aula básica para sordos de una institución educativa pública de la ciudad de Popayán. Nodos y Nudos, 42, 101-116.

Este artículo es el resultado de la investigación "Representaciones sociales que tienen las madres de familia frente a la inclusión educativa de los niños y las niñas sordos y sordas del aula básica de la Institución Educativa la Pamba, durante el periodo 2014-2016". Las autoras desean dar expreso crédito y mención a la Corporación Universitaria Autónoma del Cauca y a la Institución Educativa la Pamba por los espacios y tiempos facilitados para llevar a cabo esta investigación.

**

***
Candidata a Doctor en Ciencias de la Educación Universidad del Cauca - RUdECOLOMBIA. sol.vesga@uniautonoma.edu.co

Licenciada en Educación para la Primera Infancia. Integrante del Semillero de Investigación SEFAC de la Corporación Universitaria Autónoma del Cauca. julieth.trujillo.p@uniautonoma.edu.co

*** Licenciada en Educación Preescolar. Integrante del Semillero de Investigación SEFAC de la Corporación

Universitaria Autónoma del Cauca. karen.agudelo.r@uniautonoma.edu.co 


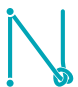

Volumen 5 N. ${ }^{\circ} 42$ enero - junio de 2017 ISSN: 0122-4328 ISSN-E: 2619-6069 pp. 101-116

\section{RESUMEN}

Este artículo muestra las actitudes de las madres de familia frente a la sordera de sus hijos, antes y después de un proceso de escolarización de cuatro años en un aula básica para sordos, en una institución educativa pública de Popayán. El método utilizado fue la teoría fundamentada. Los hallazgos presentan las actitudes que tienen las madres frente a la sordera, las cuales responden a tres momentos históricos de la vida familiar: "la ceguera ante la sordera" comprende las actitudes de las madres cuando se enteran de que su hijo es sordo; "la re-acción ante la sordera" abarca las actitudes de las madres ante la mirada de la sordera desde un enfoque clínico; y "los re-encuentros en la sordera" expresan las actitudes de las madres cuando la sordera se asume desde un enfoque socio-antropológico.

Palabras clave: actitudes; inclusión educativa; niñez, madres de familia; sordos

\section{ABSTRACT}

This paper shows the attitudes of mothers in the face of their children's deafness, before and after a four-year schooling process in a beginner's class for the deaf at a public school in Popayán. The method used was grounded theory. Findings show that the attitudes of mothers respond to three historical moments of family life: "Blindness to deafness" comprises the attitudes of mothers when they find out their child is deaf; "re-action to deafness" covers the attitudes of mothers in the face of deafness from a clinical approach; and "re-encounters in deafness" express the attitudes of mothers when deafness is assumed from a social and anthropological approach.

Keywords: attitudes; educational inclusion; childhood; mothers; deaf

\section{RESUMO}

Este artigo evidencia as atitudes das mães de família frente à surdez de seus filhos, antes e depois de um processo de escolarização de quatro anos em uma sala de aula básica para surdos, em uma instituição de ensino público em Popayan. 0 método utilizado foi a teoria fundamentada. As descobertas apresentam as atitudes das mães frente à surdez, que correspondem a três momentos históricos da vida familiar: "a cegueira ante a surdez! compreende as atitudes das mães ante o olhar da surdez desde uma abordagem clínica; e "os reencontros na surdez" expressam as atitudes das mães quando a surdez é assumida desde uma abordagem socioantropológica.

Palavras-chave: atitudes; inclusão educativa; infância; mães de família; surdos 


\section{Introducción}

La historia de la humanidad da cuenta de personas que, debido a alguna condición física, psicológica o emocional, distaban de los parámetros de "normalidad" construidos socialmente en las distintas épocas y por ese motivo fueron apartadas, rechazadas y excluidas de la participación activa en los distintos ámbitos de la sociedad (Nussbaum, 2007). Los abusos a sus derechos como ciudadanos fueron reiterativos; no solo se expresaban en las manifestaciones cotidianas de los grupos sociales, sino en el atropello de los derechos fundamentales de cualquier ciudadano (ONU, 1993). La discriminación para estas personas en condición de discapacidad' llegó a ser tan fuerte que, incluso, en algunas culturas se optaba por su muerte; por ejemplo, los espartanos los arrojaban desde montes altos, mientras que los romanos los tiraban a los ríos, los abandonaban o los sacrificaban (Patiño, Oviedo y Gerner, 2001). De esta manera, al indagar por la historia de las personas con alguna discapacidad, se encuentran tristes narraciones donde predominan prácticas de poder impuestas por los más fuertes, quienes en últimas decidian qué se hacia y qué podian hacer estas personas llamadas "raras" dentro de la estructura social imperante. Fue así como estas personas vivieron siglos de oscurantismo, pues estaban vetadas por las mismas sociedades construidas solo para algunos (González, 2011).

El caso de las personas en condición de discapacidad auditiva no fue la excepción. En la historia se narra cómo las actitudes ${ }^{2}$ de las personas estaban relacionadas con sus concepciones o representaciones; por ejemplo: en algunas épocas, si alguien era considerado "maldito" o "endemoniado", entonces era quemado en la hoguera; o, en la Edad Media, si alguien era tomado por "loco", lo encerraban en un manicomio, donde se le prestaba ayuda asistencial y se le negaban derechos fundamentales como estudiar, casarse o tener hi-

1 Este concepto lo define la onu (2008) como: "un concepto que evoluciona y que resulta de la interacción entre las personas con deficiencias y las barreras debidas a la actitud y al entorno que evitan su participación plena y efectiva en la sociedad, en igualdad de condiciones con los demás" (p. 42).

2 Según Moscovici (1979), "las actitudes son una dimensión de las Representaciones Sociales $y_{1}$ en consecuencia, es razonable decir que nos informamos y nos representamos una cosa únicamente después de haber tomado posición y en función de ella actuamos" (p. 49). jos, entre otros. Algo similar sucedia con las personas Sordas ${ }^{3}$, quienes eran aisladas de todos los procesos sociales, incluso del acceso a la escuela, pues se creía que eran incapaces de aprender (González, 2011).

Alrededor de 1620, fray Ponce de León crea en España los primeros métodos orales para comunicarse con los Sordos, acompañados por la dactilología4. Posteriormente, en Francia (siglo VIII) se empieza a reconocer las comunidades de Sordos y, por primera vez, se abren escuelas para ellos, donde se les enseña utilizando la lengua de señas ${ }^{5}$, asunto que visibilizó sus capacidades y habilidades. Sin embargo, este proceso significativo se ve afectado por la prohibición del uso de esa lengua en las escuelas para Sordos, expedida por el Congreso Internacional sobre la Instrucción de los Sordomudos (Milán, 1880), donde se promulga "la superioridad del habla sobre los signos para incorporar a los Sordos a la vida social [...] y se declara el método oral puro como el mejor" (Oviedo, 2006, p. 13). De esta manera, se ordena enseñar la oralidad como el único método válido para la educación de los Sordos en el mundo. Estas leyes estuvieron vigentes en Europa hasta 1960 (en paises como España permanecieron hasta 1980). Lo anterior condujo a un silenciamiento de la comunidad Sorda por más de un siglo, pues la gran mayoría de Sordos no lograron adquirir la oralidad y, por ende, ninguna otra lengua que les posibilitara comunicarse y desarrollar su pensamiento (Sacks, 2003).

Gracias a protestas y movimientos sociales, a partir de 1960 renació la identidad sorda y comenzó un tiempo nuevo de visibilización y reconocimiento tanto de la lengua de señas ${ }^{6}$ como de la cultura y las comunidades de Sordos en el mundo (Oviedo, 2006).

3 Patiño, Oviedo y Gerner (2001) plantean "que cuando se haga referencia a aquellos sordos que han aceptado su condición sociológica y lingüistica se utilice la palabra sordo/a con mayúscula, en oposición a las alusiones que hagan referencia a la condición puramente audiológica" (p. 7). En este artículo adoptamos esta sugerencia.

4 Consiste en representar cada letra del alfabeto mediante una configuración manual. Deletrear en dactilologia es como escribir en el aire, lo cual exige el dominio del sistema alfabético (González, 2011).

5 Se entiende por esta una lengua viso-gestual que cumple con todas las funciones del lenguaje y se usa como comunicación alternativa para aquellas personas que no pueden acceder o utilizar la lengua oral (Robles, 2012).

6 "La lengua de señas debe ocupar el mismo lugar que tienen las lenguas orales. Las lenguas de señas son aptas para todo lo que son aptas las lenguas orales. Pueden expresar los pensamientos más complejos y las ideas más abstractas, siendo adecuadas para transmitir la información y para la enseñanza" (Sánchez, 2011, p. 14). 
Antes de estos movimientos sociales, en Colombia predominaba el método oralista (Patiño, Oviedo y Gerner, 2001) y la lengua de señas no era bien vista, ni utilizada en los espacios escolares. Una vez que se inició el reconocimiento mundial de la cultura sorda y su diferencia lingüística, se creó en el país, en 1956, el Instituto Nacional para Sordos (Insor), hoy adscrito al Ministerio de Educación Nacional, que trabaja para mejorar los procesos educativos de la población Sorda a través de un enfoque socio-antropológico ${ }^{7}$ de la sordera ${ }^{8}$, bajo un método de educación bilingüe ${ }^{9}$ y bicultural ${ }^{10}$. Posteriormente, en 1984, se creó la Federación Nacional de Sordos de Colombia (Fenascol), cuyos propósitos son, entre otros, la defensa de los derechos de las personas Sordas; el desarrollo, la enseñanza e investigación de la lengua de señas colombiana y la formación de líderes Sordos.

Así pues, el Insor y Fenascol permitieron nuevos procesos de reivindicación con la población Sorda; no obstante, las personas beneficiadas fueron las de las grandes capitales del país; por el contrario, en ciudades periféricas, como Popayán, apenas hace cuatro años llegaron estas propuestas educativas y sociales. Esta demora generó un atraso educativo y social en la población Sorda de la ciudad (Cabezas, 2104), reflejado actualmente en las pocas oportunidades laborales, sociales y educativas de los Sordos adultos.

En 2012, se crea en Popayán, con la asesoría del Insor, la primera Aula Básica para Sordos ${ }^{11}$ (ABS), con el

7 Esta visión consiste en considerar al Sordo desde sus capacidades, como un integrante de una comunidad lingüistica minoritaria, que posee una lengua propia con características socioculturales propias (Veinberg, 2002)

8 La sordera desde una mirada clínica se relaciona con la pérdida de la audición y está clasificada en sordera e hipoacusia. La hipoacusia es la pérdida de audición por debajo de $90 \mathrm{~dB}$, que con o sin ayuda técnica permite acceder al lenguaje; la sordera es la pérdida de audición por encima de $90 \mathrm{~dB}$, que impide el acceso al lenguaje oral (Monsalve y Núñez, 2016)

9 Por educación bilingüe nos referimos al reconocimiento de la primera lengua (lengua de señas) de las personas sordas. Esta se utiliza como mediación para el proceso de formación de estas personas, al igual que la enseñanza escrita de la lengua mayoritaria de la comunidad oyente como una segunda lengua (Lissi, Svartholm y González, 2012).

10 La educación bicultural en los Sordos se refiere a la importancia de formar a estas personas para que se desenvuelvan en dos contextos culturales distintos: el de la cultura Sorda que es minoritaria y el de la cultura oyente que es mayoritaria, con todas las implicaciones que esto conlleva (Robles, 2012).

11 Por ley de la Nación, los estudiantes Sordos de la Educación Básica Primaria deben asistir a las Aulas Básicas para Sordos, donde se maneja el multigrado (preescolar hasta quinto de primaria) y, en compañia de un docente usuario de lengua de señas colombiana y un modelo lingüístico (Sordo adulto), los estudiantes adquieren la lengua de señas y demás aprendizajes propios de su edad mental y escolar (MEN, 2009). fin de ofrecer una educación bilingüe y bicultural a los niños y jóvenes Sordos de la ciudad. Ellos llegaron al aula con la carencia de una lengua, y con esto, todas las implicaciones emocionales, cognitivas, sociales y corporales que de alli se desprenden. Después de cuatro años de funcionamiento del ABS, se genera el interés de dirigir la mirada hacia las madres de familia de estos niños, pues la familia se convierte en un aspecto fundamental en la formación de los estudiantes, ya que son los primeros en compartir ese espacio de socialización que deja huella para toda la vida (Rincón, 2011).

De este modo, se genera un interés por comprender las actitudes que tienen las madres de familia, guiados por aspectos como los siguientes: en primer lugar, los vínculos afectivos gestados en la familia del niño Sordo (Skliar, 1997); segundo, los procesos comunicativos de este con sus madres, debido a que no comparten una misma lengua; tercero, los procesos de socialización que se afectan porque el niño Sordo no adquiere una primera lengua desde una temprana edad; y cuarto, influencia del entorno familiar del niño Sordo en la construcción de su identidad.

Los hallazgos que se presentan en este artículo se refieren especificamene a las actitudes de las madres de familia frente a la sordera en un lapso histórico-temporal y que han posibilitado o limitado aspectos esenciales en la vida de estos niños. Esta investigación se convierte en uno de los primeros referentes investigativos de la ciudad de Popayán, donde los sujetos participantes son las madres de familia de los estudiantes Sordos escolarizados. Se espera que este aporte al campo sirva para seguir construyendo escuelas y sociedades más inclusivas.

\section{Escenarios y sujetos de la investigación}

El escenario escolar de investigación es la Institución Educativa la Pamba, escuela pública adscrita a la Secretaría de Educación de la ciudad de Popayán (Cauca-Colombia). La institución cuenta con dos jornadas de atención (mañana y tarde); atiende una población que pertenece a los estratos sociales bajos; los estudiantes matriculados provienen de zonas urbanas marginales del sector suroriental de la ciudad, y en su entorno prevalecen problemáticas sociales como 
pandillas, delincuencia común, prostitución, venta y consumo de estupefacientes, entre otras.

La institución cuenta, aproximadamente, con 460 estudiantes, entre los cuales hay 9 estudiantes con sordera, 2 de ellos estudian en la Media Vocacional, tienen el apoyo de dos intérpretes ${ }^{12}$ y un docente usuario de lengua de señas colombiana, con especialidad en lengua castellana, que apoya la enseñanza del castellano escrito. Para el caso de la Educación Básica, se cuenta con el Aula Básica para Sordos (ABS), a la que asisten 6 estudiantes con sordera, que llegan al aula entre los 8 y los 15 años de edad, sin ser competentes en una lengua y con frustrantes experiencias educativas (Vesga, Lasso y Tobar, 2016).

El aula cuenta con una docente usuaria de lengua de señas colombiana y una modelo lingüístico ${ }^{13}$ (MEN, 2009). Los procesos educativos se orientan desde un enfoque socio- antropológico de la sordera, con un método bilingüe y bicultural ${ }^{14}$; para este proyecto pedagógico, por medio de la gestión de algunos de los actores educativos que convergen en el aula, se ha logrado la adquisición de recursos didácticos, tecnológicos, artísticos y deportivos dispuestos para la enseñanza y el aprendizaje de los estudiantes Sordos.

Respecto a los sujetos participantes de la investigación, son seis madres de familia de los estudiantes del ABS que pertenecen a estratos socioeconómicos bajos, viven en sectores urbanos marginales y rurales de la ciudad; no cuentan con estudios de educación secundaria y están dedicados a oficios informales, entre los que se puede destacar: coteros o cargadores de bultos, amas de casa, meseras, agricultores, entre otros. Inicialmente, se quería contar con la participación de padres hombres y mujeres, pero solo las madres de familia accedieron al proceso de investigación, pues, según ellas, son las que han estado siempre presentes en el proceso de formación de su hijo Sordo.

12 Son personas con conocimiento amplio de la lengua de señas colombiana y hacen la interpretación a la lengua castellana en distintas situaciones comunicativas (Congreso de la República, 2012).

13 Persona que muestra la lengua de señas colombiana en uso, la modela para los aprendices sordos y oyentes, también tiene el conocimiento implicito de ser y vivir como sordo y, por lo tanto, manifiesta y transmite en sus interacciones comunicativas cotidianas el patrimonio de valores de la comunidad Sorda (MEN, 2009).

14 Este método permite al niño sordo desarrollar sus potencialidades dentro de la cultura sorda y aproximarse a través de ella a la cultura oyente. Se incluyen en el proceso educativo dos lenguas y dos culturas en contextos diferenciados por roles pedagógicos (Veinberg, 2002).

\section{Metodología}

Esta investigación es de tipo cualitativo y se propone comprender las actitudes de las madres de familia frente a la sordera de sus hijos. El método utilizado fue la teoría fundamentada, de Strauss y Corbin (2002), que, según Restrepo (2013), "es una propuesta metodológica que busca desarrollar teoría a partir de un proceso sistemático de obtención y análisis de los datos en la investigación social" (p. 14). Por ende, la teoría emergente surge en relación con un análisis de categorías empíricas con sus subcategorías, que una vez analizadas con sus propiedades y dimensiones se relacionan entre sí, se someten a un proceso de descripción, comparación y conceptualización, frente al fenómeno social estudiado.

Las técnicas de recolección de información utilizadas fueron, en primer lugar, la entrevista a profundidad, definida por Mejía (2003) como "una entrevista personal, directa y no estructurada, en la que el investigador hace una indagación exhaustiva para lograr que el entrevistado hable libremente y exprese en forma detallada sus motivaciones, creencias y sentimientos" (p. 194). Es así como, a partir de una interacción personal, se crea un ambiente de confianza con el entrevistado y se logra que este exprese sinceramente aquello que, incluso, no comparte con nadie. En esta investigación las entrevistas a profundidad tuvieron como instrumento unas guias semiestructuradas, con preguntas abiertas sobre el objeto de la investigación, de carácter flexible, según lo que se generó en los diálogos con los participantes.

En segundo lugar, se utilizó la técnica del grupo focal, el cual centró su interés en evidenciar una discusión por medio de la interacción discursiva y de las opiniones de las madres de familia; alli se coordinaron procesos de interacción, discusión y elaboración de acuerdos. Esta interacción grupal que se produjo en el encuentro promovió un aumento en las posibilidades de exploración y generación espontánea de la información, como lo han documentado Bertoldi, Fiorito y Álvarez (2006); a su vez, contribuyó a la saturación de las categorias emergentes.

Para cada una de las técnicas mencionadas se aplicaron los métodos de análisis de la información, siguiendo tanto el método de comparación constante 
como procesos de codificación (abierta, axial y selectiva) y categorización (Strauss y Corbin, 2002). Posteriormente, se realizó la triangulación de la información, que consistió en yuxtaponer las perspectivas sobre un fenómeno entre las categorias teóricas, las categorías empíricas y la voz del investigador; de esto surgieron los resultados de la investigación, que se presentan en el siguiente apartado.

\section{Hallazgos}

Según Moscovici (1979), las actitudes se establecen y se organizan a partir de elementos que identifican una cultura con sus valores y creencias que se encuentran arraigados en la sociedad; así pues, al comprender las actitudes de las madres de familia frente a la sordera, se logra también entender sus conocimientos y sus creencias. Estas actitudes develadas, se presentan a continuación, agrupadas en tres categorias que a su vez responden a tres momentos históricos de la vida familiar: la primera, la ceguera ante la sordera, referida a las actitudes una vez se enteran que su hijo es Sordo; la segunda, la re-acción ante la sordera, muestra las actitudes cuando esta se aborda desde una mirada clínica; y la tercera, los re-encuentros en la sordera, cuando se asume desde un enfoque socio-antropológico.

\section{La ceguera ante la sordera}

Esta categoría presenta las actitudes que las madres de familia tuvieron cuando se dieron cuenta de que su hijo es Sordo ${ }^{15}$. Esto detona sentimientos y emociones encontrados que, a la par con los conocimientos mínimos que las madres tenían previamente respecto a la sordera y algunas creencias erradas acerca de ella, llevaron a actuar de una manera enceguecida con la condición biológica que presentaban sus hijos.

Según lo planteado por López (2014), cuando las madres se dan cuenta de la condición de Sordera de sus hijos entran en un choque emocional que genera cierto congelamiento de sus acciones y decisiones, asumiendo una actitud de ocultamiento de la realidad. Hacia los dos años de vida, las madres empiezan a comparar el desempeño de sus hijos con los avances

15 Desde la mirada clínica, un Sordo es una persona con pérdida auditiva; desde lo socio-antropológico, es una persona usuaria de lengua de señas y perteneciente a una cultura minoritaria (Fontal y Mejia, 2015) de otros niños de su misma edad e intuyen que algo no está bien. "Lo llamábamos y no nos respondia", nos dice una de las madres. Otra nos expresa que "no hablaba nada, solo hacía ruidos". Tras el ocultamiento de la realidad también se genera una actitud de búsqueda médica que corrobore o niegue lo que perciben. Ya en el sistema de salud y una vez realizado el diagnóstico médico, las madres reciben la noticia inesperada pero sospechada: sus hijos son Sordos. Algunas de las madres participantes en la investigación nos comparten lo que el médico les dijo "...ustedes deben saber que él ya no va a ser normal", "hay que hacer los trámites para el implante coclear y demás".

Así pues, al tratar de ocultar la realidad, las madres adoptan una actitud de negación, que se convierte en una reacción defensiva frente a aquello que surge desde el inconsciente y amenaza la estructura simbólica en ellos (Bornhauser y Rosales, 2015). Esta actitud es el resultado de un sentimiento de desconcierto, ya que el anhelo de ellos era tener un hijo "normal", como lo expresan dos madres participantes: "uno siente como si el mundo se le derrumbara", "Yo supe y eso me dio muy duro". Esta actitud de negación generó también discordias y culpas familiares por la posible causa de la condición de sordera de sus hijos; algunas madres de la investigación manifestaban: "él me dejó de hablar, era como ese odio hacia mí", "la culpa fue de él pues me pegó en el embarazo". Fue así como detrás de estas acciones y actitudes se configuró una creencia de incapacidad y enfermedad frente a la sordera (Medina, 2005) que detonó para algunas madres sentimientos de vergüenza familiar. Ellas expresaron: "yo no lo sacaba de la casa", "yo decía que no, no era sorda".

Según Torres (2014), estas actitudes de rechazo y silencio llevan a golpear la estructura y el ambiente familiar e inciden en los vínculos afectivos de las madres y los hijos Sordos, asunto que deja huellas imborrables en su desarrollo emocional. Las madres manifestaron cómo las actitudes de rechazo eran alimentadas por sentimientos de desesperación; en sus palabras: "Eso nunca; no lo esperamos", "Ahora, ¿qué voy a hacer?". Esta actitud se soportaba en sentimientos de tristeza y dolor familiar; por ejemplo, algunas madres decían: "yo lloraba todos los días, me preguntaba todo el tiempo ¿por qué a mí?", "yo caí 
en la depresión, no quería nada". Todo este dolor familiar aumenta los conflictos y las rupturas emocionales entre las madres; algunas madres decian: "el decidió dejarme por eso", "no pudimos vivir juntos más". Algunas madres manifiestan que al quedar con sus hijos decidieron vivir solas todo el sufrimiento que les generó tener un hijo en esta condición: "decidí no contarle a nadie", "yo sola vivir con todo ese sufrimiento".

Según la onu (2008), la construcción de las barreras sociales se da en esos primeros espacios de socialización del niño Sordo, generada por esas expresiones y manifestaciones de auto-rechazo y auto-exclusión que se viven en las dinámicas familiares al no aceptar las condiciones biológicas de sus hijos, en este caso la sordera. Algunas madres de la investigación nos narran la manera como sus esposos y algunos miembros de la familia se distanciaron totalmente de su hijo: "se alejó del niño, solo cumplía con traer lo del mercado"; "todo lo de mi hijo yo lo hago, el papá no se interesaba por nada", "mi familia no volvió a mi casa"; "ellos solo le ponían atención a su hermano oyente".

Para Moral, Valdez y Alvarado (2013), hay un proceso que surge en las familias después de todos los sentimientos de negación y depresión respecto a una condición de sus hijos: la resignación. Las madres, de alguna manera, se sobreponen a esos sentimientos adversos y empiezan a aceptar la condición de su hijo, pues sienten que ellos son los únicos que lo pueden ayudar; así lo expresan algunas de ellas: "aunque no era como yo quería, había que aceptarlo asi", "ya me eché al dolor, ya no se podía hacer nada". Siguiendo a Rodríguez (2007), esta actitud de resignación se encuentra soportada en el sufrimiento, bien sea pasivamente o bien guardando silencio; según el autor, el resignarse no permite vivir en paz o armonía con la enfermedad; por el contrario, genera gran malestar emocional.

Este malestar emocional suele generarse en las familias que aún consideran la condición de sordera como una minusvalía, una enfermedad, una anormalidad, una condición de inferioridad respecto a las personas oyentes (Skliar, 2000). Algunas madres manifiestan cómo, debido a su desconocimiento frente al tema, creían que sus hijos no podían aprender ni entender lo que sucedía en su entorno, entonces se preocuparon más por suplir sus necesidades básicas, como la casa, el alimento, el vestido, pero no el desarrollo de aspectos fundamentales como la comunicación, la educación y las normas sociales, como lo expresan algunas madres: "no le poníamos atención, cuando ya tenía hambre, ahí si"; "le señalábamos o le hacíamos las cosas; así era siempre". Este tiempo familiar, de acuerdo a lo dialogado en la investigación con las madres, fue como de adormecimiento frente a la condición de sordera de sus hijos, pues, aunque se expresa que se llegó a aceptar la condición, no se evidenciaban acciones para romper las barreras comunicativas ni lingüisticas de su hijo Sordo.

Por lo anterior, según Torres (2014), la familia en su papel relevante de primer agente socializador significante transmite valores y normas culturales a sus hijos, pero al contar con una barrera comunicativa este proceso se limita; dejando así unas marcas imborrables en la formación de los niños Sordos. Las madres de la investigación expresaron que desconocían aspectos importantes sobre sus hijos, como su lengua, su identidad y su cultura Sorda; esto las Ileva a recordar cómo en muchas ocasiones en la niñez de sus hijos asumian conductas que poco favorecian el proceso de interacción con ellos: "yo le gritaba a ver si me entendía algo", "cuando no me obedecía, yo le pegaba un pellizco", "él nunca participó en decisiones de la familia, no".

Este primer apartado presenta el soporte de las actitudes asumidas por las madres de familia de la investigación ante un anhelo frustrado, que trae como consecuencia una serie de conflictos y fracturas familiares, que a su vez recaen la mayoría de veces en el niño Sordo. Igualmente, en esta etapa las madres manifiestan el desconocimiento de las acciones afirmativas que se pueden generar en favor de las personas Sordas para que demuestren su potencial, y así puedan desarrollar a una edad temprana procesos de comunicación efectivos y afectivos. Es importante anotar que si bien algunas madres narraron estos episodios de ceguera como un asunto del pasado, aún siguen viviendo sentimientos de negación y frustración ante esta condición biológica del niño Sordo por parte de algunos familiares cercanos. 


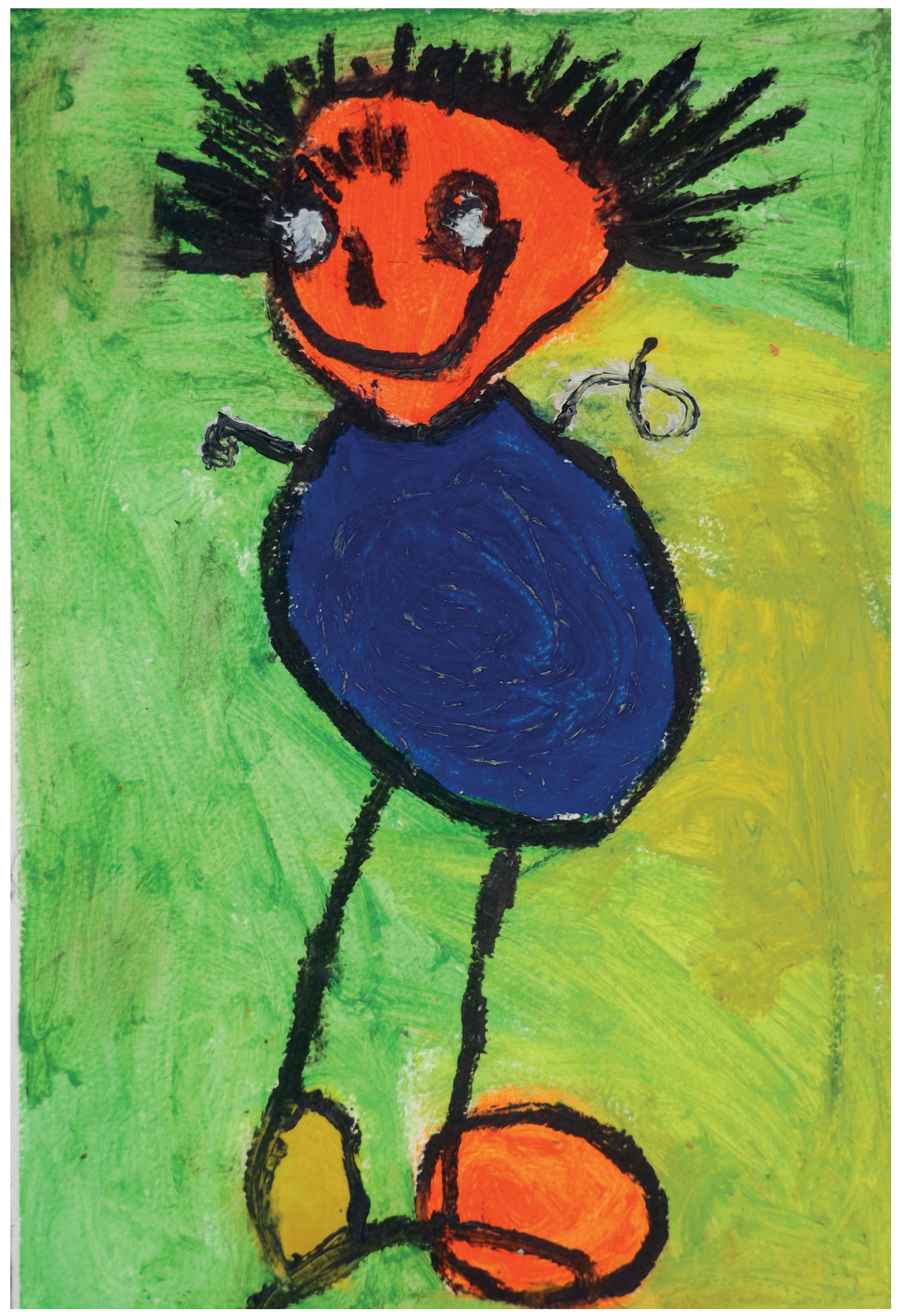

Autor: Anderson Hernandez, 4 años, grado Jardín Título : Yo

Año : 2011

Técnica : Óleo sobre cartulina 


\section{Re-acción ante la sordera}

Esta categoría presenta las actitudes que las madres de familia tuvieron frente a la sordera en una segunda etapa, en la cual, a pesar de la condición de discapacidad de su hijo, creyeron necesario brindarle las posibilidades y el apoyo para que pudiese salir adelante. El primer camino que tomaron las madres de familia fue acudir al sistema de salud y seguir sus sugerencias.

Según Monsalve y Núñez (2016), los acudientes de los niños en condición de sordera generalmente guardan la esperanza de que algún día puedan alcanzar la "normalidad" de la comunidad mayoritaria que es la oyente, es decir hay un anhelo en las madres de que sus hijos Sordos logren alcanzar una oralidad parcial o total, y con esta idea se apoyaron en los avances científicos y tecnológicos que les pudo brindar el sistema de salud, es asi como la mayoría de los niños tienen implante coclear y audifonos. De la misma manera, se puede observar cómo en esta fase las madres de familia asumen una actitud de aceptación condicionada, es decir hay una aceptación momentánea de la sordera con sus esperanzas puestas en que sus hijos algún día hablarán como ellos y lograrán procesos de comunicación. Según las madres, entonces todo sería distinto.

De acuerdo con Cabezas (2014), los procesos de aceptación de las madres frente a la sordera de sus hijos se tornan relativos dado que cada persona supera sus miedos y culpas de una manera diferente, y en este proceso influyen también sus experiencias de vida. En el caso de las madres de la investigación, estas manifestaron esfuerzos por dejar atrás sus culpas e iniciar un proceso de enfrentamiento con sus propios sentimientos negativos asumiendo ciertas acciones distintas con sus hijos, iluminadas pro la creencia de que si la sordera se podría curar, harían lo que estuviera a su alcance para lograrlo. Por ejemplo, algunas madres expresaron: "ella va a escuchar; yo no sé cómo, pero ella va escuchar", "poco a poco ella va a hablar con ayuda de las terapias".

De acuerdo con Mercado, Aizpurúa y Vicente (2012), en muchos casos las madres de los niños en condición de sordera se ven abocados a pasar por tiempos prolongados en el sistema de salud, debido a los tratamientos a los cuales son sometidos los niños para su recuperación. Esta misma situación la expusieron las madres de familia de la investigación, quienes narraron el tiempo y los costos que les generó la asistencia a todos los procedimientos y terapias ofertados por el sector salud. Sin embargo, expresaban que para ellas fue muy importante ese sacrificio porque era de alguna manera quitarse culpas generadas del proceso y así lograr avanzar, fruto de un sentimiento de esperanza que tenian respecto a la adquisición de la oralidad de sus hijos. Algunas de ellas contaban que esta etapa no fue nada fácil, pues el sistema de salud colombiano es lento en procesos tan costosos como las cirugías: "tenía que ir todos los días a terapias orales", "ya a los 5 años del niño tuvimos que colocar tutela para el implante coclear", "eran interminables filas y tiempo para ir a las citas".

Un aspecto en común en las madres de la investigación es el diagnóstico médico de sus hijos: todos estaban clasificados como Sordos profundos bilaterales, y a pesar de que dos de ellos recibieron el implante, todos utilizaban audifonos, asistían a terapias fonoaudiológicas por lo menos de dos a tres veces por semana, participaban de dos espacios escolares (la escuela regular con oyentes y un instituto privado especializado en oralización), ningún hijo de las madres participantes desarrolló la oralidad. Es importante aclarar que en otros estudios muestran cómo para el caso de Sordos hipoacústicos sí se llega a que adquieran algunos grados de competencia lingüística en la oralidad (Sánchez, 2011). De este modo, el hecho de que las madres del presente trabajo vieran con el paso del tiempo que sus hijos no adquirían la oralidad, les generó un sentimiento de incertidumbre pues su sueño era llegar a esa "normalidad" de su hijo.

Sumado a lo anterior, hasta el 2012 en la ciudad de Popayán no existía una oferta educativa para aquellos Sordos profundos de nacimiento que necesitaban otro método distinto al oral para acceder a los procesos educativos, por esta razón los hijos Sordos de las madres de la investigación hasta esta fecha manifestaban que si bien la institución oralista los acogió y les brindó una posibilidad educativa, también recuerdan acciones que en su tiempo les parecía que estaban bien pero que ahora les parece como si hubiesen perdido el tiempo. Algunas madres, por ejemplo, decian "allí lo primero era que los niños hicieran los sonidos de las letras con su boca", "la profesora les decía oralmente 
palabras y ellos trataban de repetir", "en tantos años y solo aprendieron unas palabras", "tanto esfuerzo y no se veía avances del niño". En esta institución los niños Sordos permanecen varios años de su infancia y niñez, bajo una concepción médica de la sordera donde el anhelo es llegar a esa normalidad de la comunidad mayoritariamente oyente, alcanzar el habla oral.

Al mismo tiempos que los niños Sordos estudiaban en el Instituto Oralista también asistían a una escuela regular con compañeros oyentes, pero como lo expresa Farid (2015), el hecho de que el niño Sordo no compartiera una misma lengua con sus pares y maestros, le generaba inseguridades y baja autoestima, y contribuía a que no avanzara significativamente en sus aprendizajes. De este modo, esa escuela para todos que se proclamó como integradora e inclusiva aún estaba lejos (García, Beltrán y Jutinicio, 2014) pues, según las madres de familia, se detonaron mayores decepciones y frustraciones con el proceso académico y socializador del hijo Sordo con los demás. Algunas madres expresaron: "me decian, acá no se lo podemos recibir, no hay nadie capacitado"; "¿Sordos? No tenemos la experiencia para enseñarles", "allá los compañeros no hacian sino burlarse de él", "la profesora no le tenía paciencia y a veces me lo pellizcaba". Es decir, los niños Sordos hijos de las madres de esta investigación, presentaron manifestaciones de exclusión en sus primeros años de escolaridad; esto a su vez hizo que tres de ellos construyeran un sentimiento de rechazo hacia el sistema escolar (Vesga y Vesga, 2015).

Según Parra y Peñas (2015), en los procesos de inclusión escolar poco significativos, algunos miembros de las familias van perdiendo la paciencia y la esperanza frente al desarrollo de capacidades y talentos de los niños Sordos. Esto fue lo que las madres de familia de la investigación expresaron sentir cuando se enfrentaron con las pocas oportunidades de participación brindadas a sus hijos Sordos en los espacios escolares regulares, lo que para ellos constituía un fracaso escolar; algunas madres decian al respecto: "lo tuve que sacar de esa institución", "ya llevaba tres primeros y nada que aprendia". Esto llevó a las madres de familia a asumir una actitud de confrontación con varios actores de la sociedad, enfrentándose con otras personas cuando se negaban a prestarle una adecuada atención a su hijo.
Del mismo modo, las madres consultadas explicitan que a medida que pasaban los años, crecía en ellos un sentimiento de impotencia; manifestaban que en la familia, el niño Sordo se presentaba como ajeno y distante: "permanecía solo, como si no existiera", "él se desesperaba, pues no nos podiamos entender", "Iloraba y se iba a dormir". Así pues, se observa cómo las madres de familia de este trabajo adoptaron una actitud de negligencia con sus hijos, pues las manifestaciones de resentimiento y soledad que el niño Sordo demostraba con su familia se habian naturalizado y poco se le prestaba atención. De acuerdo con Bernales (2013), esta actitud de negligencia por parte de las madres suele generar una distancia en el vínculo afectivo con su hijo Sordo, pues los niños crecen sin recibir de ellos los sistemas de normas y valores que cualquier persona en un mundo social debe aprender; por tanto, el hijo se sumerge en el silencio con mil preguntas frente a lo que acontece en su entorno.

Según algunas madres de la investigación, mientras que unos asumían actitudes de negligencia, otros expresaron adoptar una actitud de sobreprotección con sus hijos Sordos pues no querian que sufrieran ni que presentarán dificultades con su entorno. De acuerdo con estas madres, era una manera de demostrarles cuánto los amaban, y por eso sin importar la edad cronológica ni mental de los niños, algunas de ellas hacían todo lo que estaba a su alcance para atenderlos, por ejemplo: "yo no lo dejaba solo en ningún momento"; "todo se lo hacía, no le faltaba nada, pues yo siempre estaba ahí". Esta actitud de sobreprotección en algunos casos también se entendió como una creencia de incapacidad que las madres construían hacia sus hijos Sordos, y en dos casos se reflejó cómo esta actitud influyó en el desarrollo de capacidades y habilidades que su hijo demostraba en distintas situaciones cotidianas; algunas madres decian: "yo estaba pendiente para resolverle todo", "él señalaba y yo ya sabía lo que quería". Según Moreno y Granada (2014), estas actitudes de sobreprotección en algunas ocasiones llevan a procesos de inutilización del niño y a crear lazos de dependencia entre madres e hijos, contraproducentes para su desarrollo personal y social.

Una situación con relación a la sobreprotección expresada por dos madres es que, sin darse cuenta, 
fueron delegando en los hermanos del niño Sordo la responsabilidad de muchas de las actividades de rutina diaria, quienes debieron asumirlas. Al respecto Betancourt Restrepo, Pinzón, Acosta, Díaz y Bonilla (2014) expresan que en estos casos las relaciones familiares entre hermanos se van fracturando con el tiempo, pues estos adoptan el papel de segundos padres para ese hijo Sordo. Es así como las dos madres narran cómo entre algunos de los hermanos de los niños Sordos se generaron sentimientos de celos y rabia, pues aseguraban que el hermano hermano Sordo era el preferido. Frente a esto algunas madres comentaban: "su hermano también le tiene que ayudar", "él se quedaba cuidando a su hermano, mientras yo salia".

En síntesis, en esta fase de aceptación condicionada las madres manifiestan su desconocimiento respecto a la educación de los Sordos pues hasta ese momento solo conocian un método educativo para la comunidad sorda; en aquella época en la ciudad de Popayán únicamente se ofrecía y se conocía el método oral. Si bien este método funciona para los Sordos hipoacústicos, no sucede lo mismo para aquellos que tienen una condición de sordera profunda desde su nacimiento y que reciben un implante después de los 5 años, como es el caso de los niños Sordos de las madres de esta investigación, quienes comentan que no se beneficiaron con el método oral. Al no ser el adecuado para la educación de los niños Sordos, las actitudes que se presentaron en este apartado dejaron huellas en la vida familiar y personal del niño Sordo, incluso en aspectos fundamentales de su desarrollo, como identidad, cuerpo e imagen corporal (Pérez, 2012).

\section{Los re-encuentros en la sordera}

Esta categoría presenta las actitudes que las madres de familia tuvieron frente a la sordera de sus hijos en una tercera etapa, en la cual los estudiantes ingresan a una ABS en la ciudad de Popayán, donde reciben una educación bilingüe y bicultural desde un enfoque socio-antropológico. Igualmente, las madres de familia ingresan a la escuela de padres, donde se realiza una concientización acerca del papel que tienen en la formación de sus hijos Sordos. Se abordan temáticas como la lengua de señas, la identidad, la cultura Sorda, y los procesos históricos y educativos de los Sordos. Este proceso ya cumple cuatro años, y se observa cómo la familia se ha empoderado y ha ido actuando de forma más inclusiva con su hijo Sordo.

Como lo plantean Blanco y Martínez (2016), frente a la formación de sus hijos, algunas madres de familia de manera inconsciente resaltan constantemente aquello de lo que carecen, aspecto que lleva a afianzar algunas conductas y comportamientos negativos. Los autores plantean que detrás de cada actitud hay unas ideas y creencias que las respaldan, y solo cuando estas se reconocen se podría en algunos casos avanzar hacia su transformación. Esta situación se vio en algunas madres de la investigación cuando develaban sus historias de vida personales y familiares, que presentaban heridas de distinta índole al iniciar un nuevo proceso educativo en una ABS. Es así como las madres expresan que en esta nueva etapa tuvieron una actitud de desconfianza, pero también de miedo, pues fruto de la concepción clínica de la sordera aún permanecian creencias como algunas que ellos mismos mencionaban: "si aprendía la lengua de señas, no iba a poder hablar", "mejor que hablen, lo otro no creo que sea una lengua", "uno ya sabía que el niño poco iba a aprender".

De esta manera, las madres de familia narran cómo la escuela de padres donde ellos participaban en la ABS se convirtió en un espacio cálido que les brindó la oportunidad de no sentirse tan solos en el proceso educativo de su hijo. Ellos manifestaban cómo el conocer otras historias y experiencias de vida similares a la suyas hizo que bajaran un poco los niveles de ansiedad y desesperanza con sus hijos. Otro aspecto importante que expresaron que sucedió en este espacio para las madres fue la participación en conversatorios para informarse y conocer sobre ese mundo de los Sordos desde las diferencias de una lengua de señas, de otras subjetividades, de otros modos de ser y de estar en el mundo, tal como expresan Pertusa y Fernández (2004). Para algunas madres de familia fue otra manera de ver a su hijo Sordo; algunos de ellos comentaban: "pude expresar todo lo que tenía adentro que me atormentaba", "era como cambiar todas esas cosas negativas que tenía sobre mi hijo". En este espacio se consigue una actitud de apertura y las madres, por primera vez, logran 
iniciar una especie de duelo ante la condición de su hijo, lo que les permitió ir cambiando algunos sentimientos negativos que tenían y así comenzar a reconocer aspectos positivos en sus hijos que antes estaban invisibles a su mirada.

Siguiendo a Mercado, Aizpurúa y Vicente (2012), la importancia de generar espacios de reflexión con las madres de familia para llegar a procesos de introspección les posibilita a las madres ir cambiando conscientemente algunas ideas y pensamientos, lo que repercute en su bienestar $y_{1}$ a la vez, en el mejoramiento de las relaciones con su hijo Sordo, pues las actitudes también se van volviendo más conscientes. Es así como las madres de familia plantean que después de reflexionar sobre las creencias de la sordera y convivir de forma más cercana con sus hijos y de conocer y apropiarse de otras metodologías más apropiadas para ellos, en alguna medida aceptaron la condición de su hijo Sordo. Algunos de ellos expresaron: "empecé a salir con él a las calles y ya no sentía esa pena; al contrario, era como ese orgullo", "igual, con mi familia empecé a luchar para que ellos también cambiaran la forma de pensar".

Para Fontal y Mejia (2015), este proceso es muy relevante, pues, por primera vez, las madres empiezan a asumir una acción importante para ayudar a su hijo, más allá del asistencialismo. Así, plantean que se empezaron a interesar poco a poco por esos otros modos de comunicación y educación para sus hijos Sordos, sin darle toda la importancia a la condición de sordera. Las madres también expresan la manera como sus hijos Sordos empezaron a mostrar cambios en sus formas de comunicarse y de relacionarse con otras personas del entorno familiar y social; asimismo contaron cómo fueron testigos de la manera en que iniciaron un proceso de aprendizaje en las distintas áreas del saber, pues decian que la docente del aula se valía de experiencias nacionales para guiar su proceso pedagógico (Torres, 2011). Las madres de familia entonces vieron la necesidad de ellos también entrar en contacto con la lengua de señas para lograr comunicarse con sus hijos: "al principio uno como todo tieso con las manos"; "sabía uno que eso era importante para poder comunicarme con mi hijo".
Moreno y Granada (2014) plantean que al compartir una misma lengua en la familia se favorecen los vínculos afectivos entre madres e hijos y van floreciendo actitudes de respeto. Así lo ratificaron las madres de familia, quienes narraron la manera como la comunicación en la casa se fue tornando cada vez más efectiva y fluida, y algunos miembros de las familias ya empezaban a valorar las capacidades y habilidades que los niños Sordos iban demostrando en distintos espacios cotidianos y escolares. De este modo la adquisición de la lengua de señas por parte de hijos y madres generó la posibilidad de comunicación en espacios de socialización como la escuela y la casa, donde a los hijos Sordos se les abrió una puerta hacia numerosas novedades y posibilidades para formarse, como expresaron dos madres: "era una felicidad muy grande cuando pude entenderme con él", "en la casa ya lo teníamos en cuenta para distintas cosas".

De esta manera, las madres manifestaron que al iniciar a valorar a sus hijos más por sus capacidades que por sus carencias, adoptaron otras actitudes positivas que llevaron a apoyar los procesos de formación bilingüe y bicultural que estaba teniendo su hijo Sordo. Las madres de familia narran cómo el ver a su hijo avanzar en distintos aspectos de su vida les trajo sentimientos de alivio y tranquilidad; con el trascurrir del tiempo fueron cambiando la concepción de que su hijo estaba enfermo por la sordera; como lo dicen algunas madres: "empecé a ser testigo de todo lo que aprendia"; "él es muy capaz. Hay que ver cómo juega fútbol y dibuja hermoso". De este modo, la escuela dispuesta para atender a los niños Sordos según las madres fue un gran avance en la ciudad ya que abrió la posibilidad de contar con un método educativo adecuado para los Sordos profundos que no lograron desarrollar la oralidad.

Las madres de familia cuentan también como el conocer este otro método para la educación de los Sordos y participar en él logró impactar de algún modo el propio ambiente familiar, como se refleja en los avances de sus hijos Sordos en cuanto a la apropiación y utilización de un sistema de valores y normas en distintos espacios de socialización compartidos. Según algunas madres: "no volvió a ser grosero", "los berrinches que hacía, nunca más". Las madres cuentan cómo 
los niños al sentirse reconocidos y valorados también se sintieron personas importantes dentro de la familia y la escuela; esto les ayudó en su desarrollo emocional, pues se sentían queridos y respetados por los demás en sus entornos inmediatos. De este modo algunas madres de familia logran generar actitudes positivas logrando un bien-estar de su hijo Sordo.

Finalmente, en este asunto sobre el re-encuentro en la investigación, se expuso que no todos los Sordos son iguales, y que a lo largo de la historia de la educación para Sordos se ha desarrollado un método distinto al oralista, el bilingüe y bicultural que se utiliza para a aquellos que por causa de su sordera profunda no alcanzan la oralidad, e ingresan a ambientes escolares donde tienen la posibilidad de adquirir su lengua de señas y a través de ella jalonar procesos comunicativos que los guían a comprender y a expresar su mundo en interacción con los demás. Las madres de familia al entender y conocer otros métodos para la educación de los Sordos también logran cambiar algunas ideas y creencias, lo que se materializa en nuevas actitudes de respeto y reconocimiento; la familia empieza a recobrar su papel fundamental en la formación de las personas Sordas, caminando hacia la construcción de ese lazo de protección y a la vez de apoyo que todo niño y joven requiere para su educación.

\section{Conclusiones}

Cuando se realizan procesos de investigación como este, cuyo propósito fue comprender las actitudes de los sujetos, se deben tener en cuenta, además de sus acciones corporales, las ideas, creencias y concepciones que acompañan la base de información para el resultado de sus prácticas, por medio de las cuales las personas se presentan ante el mundo y ante los demás. Por esta razón en este trabajo se mostraron no solo las actitudes de las madres de familia respecto a la sordera de sus hijos, sino también esas ideas y creencias que acompañaron tales actitudes. Cabe destacar que las experiencias de vida que tuvieron llas madres también forman parte de lo que han construido como creencias respecto a la sordera, y que los llevó a actuar de una manera determinada en algún momento.

Respecto a las familias que cuentan con un integrante Sordo, es necesario que las madres de familia conozcan los distintos métodos que existen para la educación de los Sordos, para que con base en las características y potenciales de cada niño o joven Sordo se le pueda brindar la mejor opción. En este sentido, algunos Sordos hipoacústicos por medio del método oralista han podido desarrollar su primera lengua oral y, por ende, todos sus otros procesos de desarrollo humano. Pero para el caso de esta investigación se pudo entender cómo para los Sordos profundos el método bilingüe y bicultural es el más adecuado ya que les permite desarrollar procesos comunicativos, cognitivos y emocionales a través del uso de la lengua de señas colombiana, que se convierte en su primera lengua.

Desde el sector educativo, para la situación de ciudades marginales del país es importante avanzar en la creación y el fortalecimiento de las ABS donde se utiliza el método bilingüe y bicultural como una opción educativa para los Sordos profundos, de tal manera que se les garantice pleno desarrollo e igualdad de oportunidades y de participación con respecto a los niños y jóvenes oyentes. Igualmente es en estos espacios educativos donde se avanza hacia la construcción de una educación inclusiva, en la cual se da cabida al concepto de diferencia y se reconoce la posibilidad de educar a cualquier persona una vez se identifican y potencializan sus capacidades.

Otro aspecto importante que nos permite reflexionar el desarrollo de la investigación es la importancia de involucrar a las madres de familia en el proceso de formación de los hijos Sordos, con mayor razón en el caso educativo en que se aplica el método bilingüe y bicultural, donde los niños Sordos empiezan a adquirir su lengua de señas y por ende se requiere que en su casa compartan un mismo código lingüistico para mejorar en los procesos comunicativos en el entorno familiar. Igualmente se hace relevante que las madres conozcan aspectos de la cultura y la identidad sorda.

Se requiere de la misma manera que desde la escuela se trabaje para empoderar a las madres de familia respecto a la política pública y las leyes colombianas a favor de la población Sorda, para que se conviertan en veedores ciudadanos y trabajen de la mano con sus hijos Sordos para exigir los ajustes razonables para su acceso, permanencia y participación en distintos sectores y de esta manera avanzar hacia una sociedad más incluyente. 
Otro aspecto importante es que desde las normales e instituciones de educación superior encargados de la formación a maestros se contemplen en los planes de estudio y en los procesos de práctica pedagógica e investigativa aspectos relacionados con la educación inclusiva, donde también se aborden asuntos sobre la población Sorda, sus dos métodos educativos actualmente existentes en Colombia, la lengua de señas colombiana, la cultura sorda, entre otros, con el propósito de generar una concientización y formación en este campo. Se espera que así las regiones cuenten con capacidad instalada y profesionales que se unan para trabajar de la mano con este tipo de población vulnerable.

Y para finalizar, es necesario seguir avanzando en la realización de investigaciones comprehensivas en lugares periféricos de Colombia, como Popayán, para visibilizar esos procesos y experiencias locales respecto a la educación inclusiva, para que con el tiempo lleven a un empoderamiento de los procesos inclusivos de la región y así contar con argumentos que se tomen de las necesidades del contexto, como base para incidir en la política pública de la región y en los planes de desarrollo que actualmente se ejecutan en el municipio y en el departamento.

\section{Referencias}

Bernales, S. (2013). Negligencia familiar y negligencia institucional. Consideraciones desde la intervención psicosocial. De Familias y Terapias, 34, 23-47.

Bertoldi, S., Fiorito, M. y Álvarez, M. (2006). Grupo focal y desarrollo local: aportes para una articulación teórico-metodológica. Ciencia, Docencia y Tecnología, 17(3), 111-131.

Betancourt, Y., Restrepo, J., Pinzón, S., Acosta, J., Diaz, M. y Bonilla, C. (2014). Vinculo afectivo en pares y cognición social en la infancia intermedia. International Journal of Psychological Research, 7(2), 51-63.

Blanco, A. y Martínez, J. (2016). Concepciones sobre la crianza: el pensamiento de madres y padres de familia. Liberabit, 22(1), 31-41.

Bornhauser, N. y Rosales, P. (2015). Lugares de la negación en la obra freudiana. Revista Latinoamericana de Psicopatología Fundamental, 18(1), 33-46. Recuperado de http://www.redalyc.org/pdf/2330/233038415003.pdf

Cabezas, R. (2014). Compartiendo algunas reflexiones sobre la inclusión educativa de personas sordas. Recuperado de: http://www.culturasorda.eu/resources/
Cabezas_Reflexiones_inclusion_educativa_personas sordas_2014.pdf

Congreso de la República (2012). Sentencia Corte Constitucional 128. Sobre intérprete para personas sordas. Recuperado de http://www.alcaldiabogota.gov.co/sisjur/normas/ Norma 1.jsp?i=349

Farid, M. (2015). Escuelas normales y formación de educadores desde una educación para niños con discapacidad. Historia de la Educación Latinoamericana, 17(25), 35-50.

Fontal, A. y Mejia, C. (2015). Construcción del conocimiento de las personas sordas: una aproximación a sus caracteristicas socio-familiares. Informes Psicológicos, 15(2), 47-66. Recuperado de http://dx.doi.org/10.18566/infpsicv15n2a0

García, D., Beltrán, H. y Jutinico, M. (2014). Dilemas y desafios de la integración educativa de personas en situación de discapacidad. Reflexiones sobre la experiencia en la ciudad de Bogotá. Bogotá: Universidad Distrital Francisco José de Caldas. Recuperado de http://editorial.udistrital.edu.co/ contenido/c-112.pdf

González, V. (2011). Un acercamiento histórico a la comunidad Sorda de Bogotá. Proyecto Cátedra. Recuperado de: http://www.fenascol.org.co/SEDasignaturaLSC/doctos/ HISTORIA2.pdf

Lissi, M., Svartholm, K. y González, M. (2012). El enfoque bilingüe en la educación de sordos: sus implicancias para la enseñanza y aprendizaje de la lengua escrita. Estudios Pedagógicos, 38(2), 299-320. Recuperado de http://www. scielo.cl/pdf/estped/v38n2/art19.pdf

López, J. (2014). Familia, escuela y diversidad funcional. Revista Internacional de Audición y Lenguaje, Logopedia, Apoyo a la Integración y Multiculturalidad, 4(2), 74-90.

Medina, E. (2005). Representaciones y políticas de la educación sobre los Sordos y la sordera en Colombia. Educación y Pedagogía, 17, 71-81. Recuperado de http://www.cultura-sorda.eu/resources/Medina_Moneada_Representaciones_politicas_educacion_sordos_Colombia_2005.pdf

Mejía, J. (2003). De la construcción del conocimiento social a la práctica de la investigación cualitativa. Investigaciones Sociales, 11, 179-197. Recuperado de: http://sisbib. unmsm.edu.pe/bibvirtualdata/publicaciones/inv_sociales/ n11_2003/a10.pdf

Mercado, E., Aizpurúa, E. y Vicente, L. (2012). Caracteristicas, percepciones y necesidades sociales de los niños y niñas con discapacidad y sus familias. Portularia: Revista De Trabajo Social, 12(2), 69-80. Doi:10.5218/PRTs.2012.0045

Ministerio de Educación Nacional. (2009). Decreto 366, por medio del cual se reglamenta la organización del servicio de apoyo pedagógico para la atención de los estudiantes con discapacidad y con capacidades o con talentos excepcionales en el marco de la educación inclusiva. 
República de Colombia. Recuperado de http://www.mineducacion.gov.co/1621/articles-182816_archivo_pdf_ decreto_366_febrero_9_2009.pdf

Ministerio de Educación Nacional. (2011). Los modelos lingüisticos sordos en la educación de estudiantes sordos. Bogotá: MEN.

Monsalve, A. y Núñez, F. (2016). La importancia del diagnóstico e intervención temprana para el desarrollo de los niños sordos: los programas de detección precoz de la hipoacusia. Intervención Psicosocial, 15(1), 7-28. Recuperado de http://scielo.isciii.es/scielo.php?script=sci_arttextEtpid=S1132-05592006000100002\&lng=es.

Moral, J., Valdez, J. y Alvarado, B. (2013). El significado psicológico de las cinco fases del duelo propuestas por Kübler-Ross mediante las redes semánticas naturales. Psicooncología, 10 (1), 109-130. Recuperado de: http://revistas.ucm.es/index.php/PSIC/article/view/41951

Moreno, M. y Granada, P. (2014). Interacciones vinculares en el sistema de cuidado infantil. Revista Latinoamericana de Ciencias Sociales, Niñez y Juventud, 12(1), 121-139. Doi:10.11600/1692715x.1216052513

Moscovici, S. (1979) El psicoanálisis, su imagen y su público. Buenos Aires: Huemul.

Nussbaum, M. (2007). Las fronteras de la justicia: consideraciones sobre la exclusión. Barcelona: Paidós.

Organización de las Naciones Unidas. (1993). Conferencia Mundial de Derechos Humanos. Viena: autor.

Organización de las Naciones Unidas. (2008). Convención sobre los Derechos de las Personas con Discapacidad. Nueva York. Recuperado de http://www.ohchr.org/Documents/ Publications/AdvocacyTool_sp.pdf

Oviedo, A. (2006). El lazo azul como símbolo de la lucha de la comunidad sorda. Recuperado de http://www.cultura-sorda.eu/resources/Blue_ribbon_espanol.pdf

Parra, E. y Peñas, O. (2015). El niño con discapacidad: elementos orientadores para su inclusión social. Salud Uninorte, 31(2), 329-346. Doi:10.14482/sun.30.1.4309

Patiño, L., Oviedo, A. y Gerner, B. (Eds.) (2001). El estilo sordo: ensayos sobre comunidades y culturas de las personas sordas en Iberoamérica.(vol. 2). Santiago de Cali: Universidad del Valle.

Pérez, M. (2012). Cuerpo, escuela y sociedad en la construcción de imagen corporal. Nodos y Nudos, 4(32), 101-108. Recuperado de http://revistas.pedagogica.edu.co/index. php/NYN/article/view/1903/1877

Pertusa, E. y Fernández, M. (2004). El valor de la mirada: sordera y educación. España: Universidad de Barcelona.

Restrepo, D. (2013). La teoría fundamentada como metodología para la integración del análisis procesual y estructural en la investigación de las representaciones sociales.
Revista ces Psicología, 6(1), 122-133. Recuperado de http:// revistas.ces.edu.co/index.php/psicologia/article/view/2579

Rincón, M. (2011). La familia como escenario de socialización para la convivencia ciudadana. Eleuthera, 7, 116-132. Recuperado de http://eleuthera.ucaldas.edu.co/downloads/Eleuthera7_8.pdf

Robles, M. (2012). Tendencia educativa bilingüe y bicultural para la educación del sordo: un nuevo camino hacia la inclusión. Unirevista, 1, 78-86. Recuperado de https:// dialnet.unirioja.es/servlet/articulo?codigo $=4043209$

Rodríguez, X. (2007). Una mirada reflexiva hacia el niño. La Habana: Pueblo y Educación.

Sacks, O. (2003).Veo una voz. Barcelona: Anagrama.

Sánchez, C. (2011). Los Sordos: personas con discapacidad. Recuperado de http://www.cultura-sorda.org/wp-content/ uploads/2015/03/Sanchez_C_Sordos_personas_discapacidad_2011.pdf

Skliar, C. (1997). La educación de los sordos: una reconstrucción histórica, cognitiva y pedagógica. Mendoza: Ediunc.

Skliar, C. (2000). "Discursos y prácticas sobre la deficiencia y la normalidad. Las exclusiones del lenguaje, del cuerpo y la mente". En P. Getili, Códigos para la ciudadanía. La formación ética como práctica de la libertad. Buenos Aires: Santillana.

Strauss, A. y Corbin, J. (2002). Bases de la investigación cualitativa. Técnicas y procedimientos para desarrollar la teoría fundamentada. Medellín: Universidad de Antioquia.

Torres, E. (2011). Las relaciones aditivas en un aula integrada: el caso de la deficiencia auditiva. Nodos y Nudos, 3(30), 31-44. Recuperado de http://revistas.pedagogica.edu.co/ index.php/NYN/article/view/957/972

Torres, M. (2014). El papel de la familia ante la socialización de un menor sordo. Revista Internacional de Audición y Lenguaje, Logopedia, Apoyo a la Integración y Multiculturalidad, 4(2), 70.

Veinberg, S. (2002). La perspectiva socioantropológica de la sordera. Recuperado de http://www.sancristobal.amgr.es/ signos/wp-content/uploads/2011/06/Veinberg_perspectiva_socioantropologica_sordera.pdf

Vesga, L. y Vesga, J. (2015). Una exclusión que se perpetúa: tensiones entre docentes, niños sordos y niños oyentes en escenarios escolares de Popayán. Revista Virtual Universidad Católica del Norte, 46, 115-128. Recuperado de http://revistavirtual.ucn.edu.co/index.php/RevistaUCN/ article/view/703/1230

Vesga, L. Lasso, D. y Tobar, M. (2016). Adquisición tardia de la primera lengua: experiencia escolar de niñas y niños Sordos de una institución educativa pública en la ciudad de Popayán (Cauca). Katharsis, 22, 87-113. Recuperado de http://revistas.iue.edu.co/index.php/katharsis 


\section{DIÁLOGO DEL CONOCIMIENTO}

En este artículo se realiza un análisis desde la mirada de las madres de hijos sordos en la ciudad de Popayán. Inicia con una contextualización de la sordera desde la historia de la humanidad, la cual lleva al lector a entender los procesos de emancipación de esta población, al alejarse de una visión clínica de la discapacidad y centrarse en la visión socioantropológica de los sordos como sujetos de derechos y deberes.

Resulta interesante el análisis de las categorias propuestas por las autoras del texto, pues existen pocas investigaciones que apunten a reconocer la importancia de la familia en todo el proceso social del sujeto sordo. De esta manera, la primera categoría denominada La ceguera ante la sordera recoge un momento importante en la vida del sujeto sordo, ya que para el seno de la familia no es asunto fácil aceptar la condición del nuevo integrante, pues se recibe como una noticia inesperada y en algunas ocasiones desesperanzadora.

La segunda es Ilamada Re-acción ante la sordera y presenta un segundo momento en la vida de las madres de los hijos sordos, teniendo en cuenta que ellas empiezan a creer que es necesario brindar posibilidades a sus niños sordos e inician una búsqueda por alcanzar la "normalidad" a conveniencia de los esquemas familiares y sociales. En esa situación, las madres aún no reconocen a la persona sorda como sujeto capaz, sino que intentan lograr procesos de comunicación oral con la ayuda de aparatos tecnológicos o cirugias. El sujeto sordo aún está marcado por la lucha familiar que implica la aceptación, los sentimientos negativos hacia su condición y sus propios miedos ante lo desconocido.

Finalmente, todo el recorrido del texto presenta la tercera categoria que implica un Re-encuentro en la sordera, en el que la escuela cumple un papel fundamental para el sujeto sordo. El espacio escolar le permite a ese niño sordo identificarse, encontrarse e incluso empoderarse de su identidad y cultura. Este Re-encuentro implica para las madres hallar esperanza y conocer el mundo de los sordos a partir de las historias de otras mujeres como ellas; aunque para algunos autores la condición de no aceptación de la familia resulta un asunto poco relevante en la vida de los sujetos sordos.

En general, todo el recorrido del artículo es una invitación a los lectores a reflexionar sobre la condición del sujeto sordo desde otras miradas; para las universidades es un llamado hacia la realización de investigaciones que permitan visibilizar procesos con esta población y la preparación de los futuros profesionales en la atención a la diversidad.

Lyda Solange Prieto Soriano 